\title{
Influences of operational parameters on phosphorus removal in batch and continuous electrocoagulation process performance
}

\author{
Dinh Duc Nguyen ${ }^{1,2} \&$ Yong Soo Yoon ${ }^{3} \&$ Xuan Thanh Bui ${ }^{4,5} \&$ Sung Su Kim² \& \\ Soon Woong Chang ${ }^{2} \&$ Wenshan $\mathrm{Guo}^{6} \&$ Huu Hao Ngo ${ }^{6}$ \\ 1 Department for Management of Science and Technology Development \& Faculty of Environment and \\ Labour Safety, Ton Duc Thang University, Ho Chi Minh City, Vietnam \\ 2 Department of Environmental Energy Engineering, Kyonggi University, Suwon, Republic of Korea \\ 3 Department of Chemical Engineering, Dankook University, Yongin, Republic of Korea \\ 4 Faculty of Environment and Natural Resources, Ho Chi Minh City University of Technology, Ho Chi \\ Minh City, Vietnam \\ 5 Faculty of Food and Environment, Dong Nai Technology University, Dong Nai, Vietnam \\ 6 Centre for Technology in Water and Wastewater, School of Civil and Environmental Engineering, \\ University of Technology, Sydney, NSW 2007, Australia \\ * Corresponding authors. E-mail address: swchang@kyonggi.ac.kr (Soon Woong Chang) and \\ HuuHao.Ngo@uts.edu.au (Huu Hao Ngo).
}

\begin{abstract}
Performance of an electrocoagulation (EC) process in batch and continuous operating modes was thoroughly investigated and evaluated for enhancing wastewater phosphorus removal under various operating conditions, individually or combined with initial phosphorus concentration, wastewater conductivity, current density, and electrolysis times. The results revealed excellent phosphorus removal (72.7-100\%) for both processes within 3-6 min of electrolysis, with relatively low energy requirements, i.e., less than $0.5 \mathrm{kWh} / \mathrm{m}^{3}$ for treated wastewater. However, the removal efficiency of phosphorus in the continuous EC operation mode was better than that in batch mode within the scope of the study. Additionally, the rate and efficiency of phosphorus removal strongly depended on operational parameters, including wastewater conductivity, initial phosphorus concentration, current density, and electrolysis time. Based on experimental data, statistical model verification of the response surface methodology (RSM) (multiple factor optimization) was also established to provide further insights and accurately describe the interactive relationship between the process variables, thus optimizing the EC process performance. The EC process using iron electrodes is promising for improving wastewater phosphorus removal efficiency, and RSM can be a sustainable tool for predicting the performance of the EC process and explaining the influence of the process variables.
\end{abstract}

Keywords: Electrocoagulation; Iron electrode; Phosphorus removal; Energy consumption; Response surface methodology

\section{Introduction}

In recent decades, the link between eutrophication and algal blooms has come to light and become a global issue (Heisler et al. 2008, Ye et al. 2016). Both of these phenomena have been identified as potential serious threats to natural water resources and aquatic ecosystems and pose risks to human health via food chains due to toxic algal species (Anderson et al. 2008, 2002, Sommariva 
et al. 1997). These phenomena have been ascribed mainly to surplus phosphorus concentrations in effluents, primarily coming from agricultural runoff, sewage, and industrial wastewater treatment plants (WWTPs) (Rajeshwar and Ibanez 1997, Lai et al. 2011, Nguyen et al. 2016, Ye et al. 2016), which leads to phosphorus accumulation exceed balancing of the receiving water (Conley et al. 2009, Sommariva et al. 1997). Furthermore, to prevent negative impact and improve environmental quality, national discharge regulations for residual phosphorus concentrations in effluents have become increasingly stringent. Hence, existing WWTPs require retrofitting with efficient and compact technologies that can be easily integrated in order to upgrade/improve the efficiency of phosphorus removal and capacity expansion (Nguyen et al. 2014b, Tran et al. 2012, Wang et al. 2015).

Therefore, advanced/innovative technological solutions and tools (such as higher efficiency handling of phosphorus loading, more compact size, less operator assistance, less energy consumption, capability of treating large quantities, and modular expansion) are urgently needed for treating and controlling residual phosphorus before it is discharged into the environment, in order to minimize negative environmental impacts.

Thus far, a wide range of treatment technologies is available for reducing phosphorus in effluents and they can be classified into two main groups as follows. (i) The first group includes physicochemical treatment methods such as precipitation (Al-Harahsheh et al. 2014, Huang et al. 2015), ion exchange, and adsorption (Li et al. 2006, Lin et al. 2014, Yildiz 2004). These techniques often have to use a variety of reagents (for $\mathrm{pH}$ adjustment, coagulation, flocculation, etc.) and multiple devices, have high energy requirements, and produce a large amount of sludge (Huang et al. 2017, Li et al. 2006, Tran et al. 2012, Zelmanov and Semiat 2015), therefore requiring complex operations (because of the dependence on many operation parameters). As a result, they might not be economical, flexible, nor effective enough to produce high-quality effluents. (ii) The second group includes biological treatment methods, which are more common and attractive than physicochemical treatments (Ye et al. 2016) because they can simultaneously remove many contaminants (e.g., BOD, COD, nitrogen). However, these methods require reactors with large capacities, and the phosphorus removal efficiency is still modest (less than 30\%) (Deliyanni et al. 2007, Sommariva et al. 1997), because a small portion of phosphate is taken up and stored in the microbial biomass in the activated sludge, ultimately resulting in the removal of excess sludge that is rich in phosphates (Hosni et al. 2007, Monclús et al. 2010, Yang et al. 2010).

Recently, to meet new requirements for the removal of pollutants (e.g., phosphorus and arsenic), considerable attention has been paid to the electrocoagulation (EC) process, using aluminum or iron electrodes. Positive results have been obtained, such as having high efficiency, being economic and compact, requiring simple operation, and generating little sludge during treatment, in addition to possibly not requiring the addition of any chemicals (Bayar et al. 2014, Chen 2004, Huang et al. 2017, Lacasa et al. 2011, Mollah et al. 2004). Additionally, the electrodes are available worldwide at reasonable cost (Can et al. 2014, Chen 2004, Nguyen et al. 2016, Tran et al. 2012). Despite the proven usefulness of the EC process, however, its application has not yet been fully utilized as a significant technological advantage in improving the critically needed phosphorus treatment procedure. The main mechanism of the EC process for phosphorus removal is the generation of metal and hydroxyl ions from the anode and cathode, respectively. These ions rapidly form 
coagulant species, and as a result, they can absorb and/or precipitate contaminants, which are then separated by sedimentation, filtration, or flotation (Bayar et al. 2013, Chen 2004, Daneshvar et al. 2006, Nguyen et al. 2014a). However, virtually all prior studies mainly focused on evaluating the effectiveness of phosphorus removal in wastewater by changing one or two parameters, while keeping the remaining parameters fixed. For a system with multiple dependent variables, this approach is unlikely to have practical application and cannot simultaneously assess the level of interaction among the variables.

Therefore, for a better understanding of potential EC application, it is essential to solve these problems. In the present work, we mainly aimed to investigate the EC performance of phosphorus removal in batch operating mode (BOM) and continuous operating mode $(\mathrm{COM})$ using synthetic wastewater (SWW) under various experimental conditions (i.e., initial phosphorus concentration, wastewater conductivity, current density, and electrolysis time). We verified whether the statistical model of response surface methodology (RSM) was applicable to describe correctly the effects of simultaneously operational variables on the response functions and optimized the EC performance based on experimental findings. Energy consumption, iron consumption, and the ratio of iron consumption to phosphorus removal were also evaluated.

\section{Materials and methods}

\subsection{Preparation of the wastewater}

The composition of SWW used in the experiments was prepared by dissolving various concentrations of sodium chloride $(\mathrm{NaCl}, 99.5 \%)$ and potassium dihydrogenophosphorus $\left(\mathrm{KH}_{2} \mathrm{PO}_{4}\right.$, $98 \%$ ) in tap water depending on the required concentrations of phosphorus $(1-3 \mathrm{mg} / \mathrm{L})$ and conductivity $(455-1152 \mu \mathrm{S} / \mathrm{cm})$. The initial $\mathrm{pH}$ value $(6.22-7.26)$ of SWW was adjusted using sodium hydroxide $\left(\mathrm{NaOH}, 99 \%\right.$, South Korea) and sulfuric acid $\left(\mathrm{H}_{2} \mathrm{SO}_{4}, 99.9 \%\right.$, South Korea).

\subsection{Experimental set-up and sampling}

BOM and COM systems are shown in Fig. 1a, b, respectively. Each system and experimental scheme used in this study are described in detail by (Nguyen et al. 2016) and briefly as follows.

A batch EC system (Fig. 1a) was set up in a 3534-mL polyacrylate reactor with rectangular parallelpiped geometry and a working volume of $3000 \mathrm{~mL}$. A pair of cylindrical iron electrodes of the same height $(130 \mathrm{~mm})$ were fixed in concentric cylinders with a gap of $26.75 \mathrm{~mm}$ between the two electrodes and immersed in the solution (wastewater). Internal and external cylindrical electrodes had diameters of 57 and $110.5 \mathrm{~mm}$, respectively, corresponding to a surface area of 233 and $451 \mathrm{~cm}^{2}$, respectively. These electrodes were connected directly to a DC power supply (Sunchang Electronic Co., Ltd., South Korea), which could provide direct current (0-15 A) and voltage (0$30 \mathrm{~V}$ ) at the desired values. A lab stirrer and portable probes for temperature, $\mathrm{pH}$, and conductivity were also mounted in the reactor.

A continuous EC system (Fig. 1b) consisted of a $200 \mathrm{~L}$ raw wastewater holding tank that was mounted with a lab stirrer to ensure complete mixture of the contents. The system was connected to a peristaltic pump for continuous supply of raw wastewater at different flow rates into the EC 
compact device and a DC power supply (Sunchang Electronic Co., Ltd., South Korea) that was connected to electrodes to supply the direct current. The EC compact device had a polyacrylate cylindrical distribution box at the bottom and two fixed concentric coaxial cylinder iron electrodes at the top. Internal and external cylindrical iron electrodes had working surface areas of $1700 \mathrm{~cm}^{2}$ (57 mm inside diameter $\times 945 \mathrm{~mm}$ height) and $3300 \mathrm{~cm}^{2}(110.5 \mathrm{~mm}$ outside diameter $\times 1000 \mathrm{~mm}$ height), respectively. The gap between the electrodes was $26.75 \mathrm{~mm}$. The wastewater from the cylindrical distribution box of the EC device flowed from the bottom up in an annular region between two coaxial cylinder electrodes and then overflowed into the inner electrode prior to discharge.

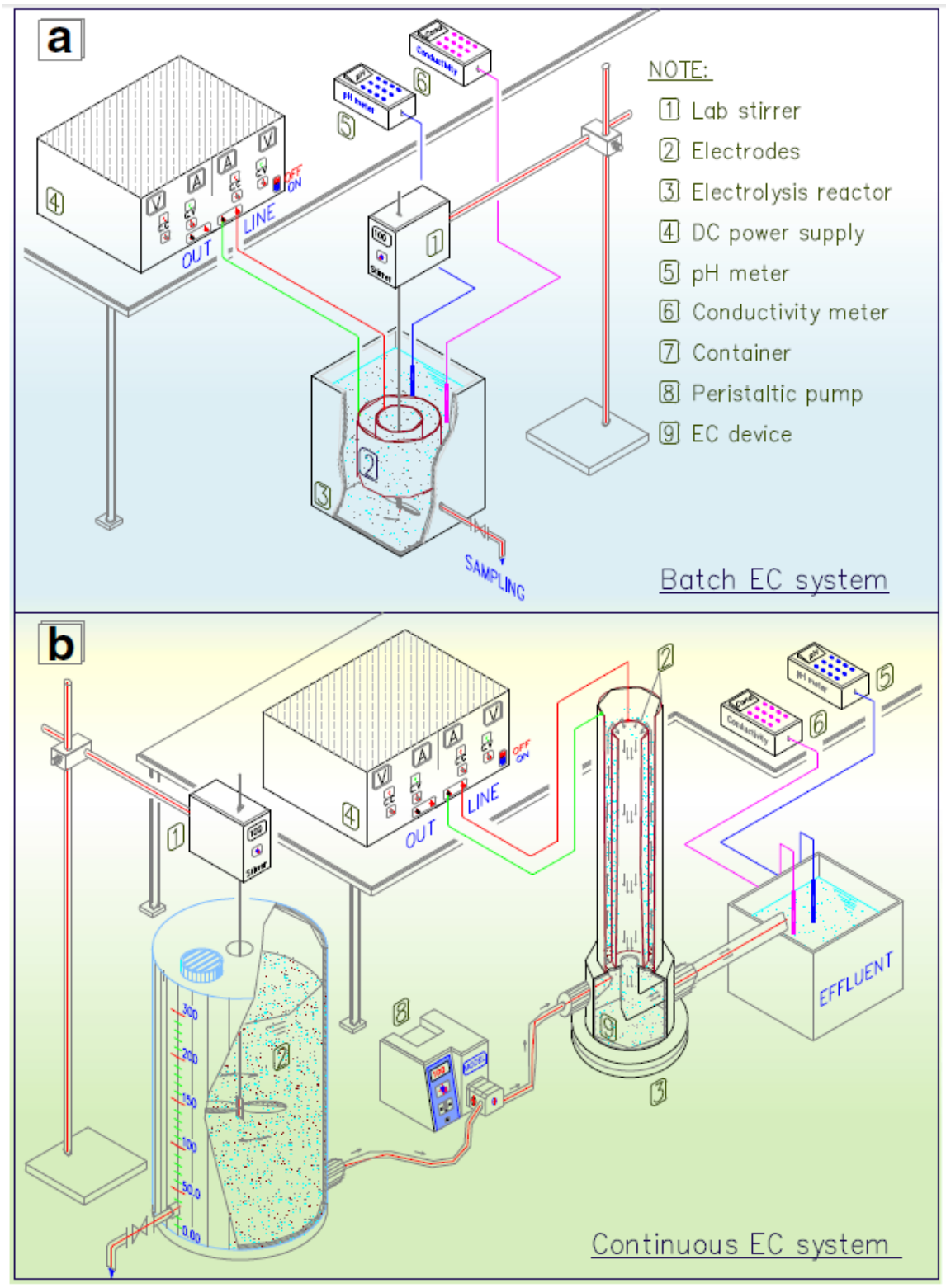

Fig. 1 Schematic diagram of the electrocoagulation system for batch operating mode (a) and continuous operating mode (b) 


\section{Calculations}

Removal efficiency $(R, \%)$ was calculated using Eq. 1 :

$$
R(\%)=\frac{C_{\mathrm{t}}-C_{\mathrm{o}}}{C_{\mathrm{o}}} \times 100
$$

where $C_{\mathrm{t}}$ is the influent concentration of phosphorus (mg TP/L), and $C_{\mathrm{o}}$ is the effluent concentration of phosphorus (mg TP/L).

The current density (CD) was calculated via Eq. 2 as follows:

$$
\mathrm{CD}\left(\mathrm{A} / \mathrm{m}^{2}\right)=\frac{I}{\left(A_{1}-A_{2}\right) / 2}
$$

where $I$ is the average current intensity (A), $A_{1}$ is the area of the inner electrode $\left(\mathrm{m}^{2}\right)$, and $A_{2}$ is the area of the outer electrode $\left(\mathrm{m}^{2}\right)$.

The efficiency of the EC process in removing contaminants strongly depends on the amount of iron from the electrodes dissolved in the wastewater. This was determined theoretically using Faraday's law to estimate the value (Eq. 3).

$$
m_{\text {anode }}(\mathrm{g})=\left(\frac{I \times t}{F}\right) \times\left(\frac{M}{z}\right)
$$

where $m_{\text {anode }}$ is the anode mass dissolved $(\mathrm{g}), t$ is the electrolysis time (s), $F$ is the Faraday constant $(96,485 \mathrm{C} / \mathrm{mol}), M$ is the molar mass of the substance $(55.847 \mathrm{~g} / \mathrm{mol})$, and $z$ is valence number of ions.

Specific energy consumption (SEC) per cubic meter of treated wastewater $\left(\mathrm{kWh} / \mathrm{m}^{3}\right)$ is a very important economical parameter of the EC process. The specific SEC was calculated using the following equation (Eq. 4) (Akbal and Camc1 2011, Martínez-Huitle and Brillas 2009).

$$
\operatorname{SEC}\left(\mathrm{kWh} / \mathrm{m}^{3}\right)=\frac{U \times I \times t}{V \times 3.6}
$$

where $U$ is the average cell voltage $(\mathrm{V})$, and $V$ is the volume of the cell (L).

\subsection{Data analysis}

The data were analyzed using Microsoft Excel 2010 with a data analysis add-in program (ToolPak) and a trial version of Minitab 17 (Minitab Inc., USA).

\subsection{Analytical methods}

Throughout the experiments, all treated wastewater and effluent samples from the reactor were collected in clean high-density polyethylene (HDPE) bottles over a predetermined period, and proper laboratory protocols for sampling, preservation, and storage of specimens were always followed. All samples were filtered with $0.45-\mu \mathrm{m}$ glass microfiber filters before analysis. The water quality parameters of suspended solids (SS), total phosphorus (TP), electrical conductivity, voltage, and $\mathrm{pH}$ were analyzed according to standard methods as described in detail in (Nguyen et al. 2014a). 


\section{Results and discussion}

\subsection{Batch EC system performance}

To determine the optimum electrolysis time and electrical conductivity needed to achieve the best TP removal results, experiments were conducted by manipulating these variables, while maintaining applied voltage, electrical conductivity, and initial TP concentration at consistent levels through several runs. The experiments were executed in several steps. In each step, one variable was changed and then their optimum value was proposed for the next part of the experiment. The goal was to arrive at the optimum conditions for phosphorus removal from wastewater by employing the EC process. Experiments were conducted using SWW, and the specific characteristics and operating conditions of each experiment are summarized in Table 1.

Variations in TP concentration, $\mathrm{pH}$ values, TP removal efficiency, SEC, mass ratio of Fe/TP, and specific iron consumption (SIC) as a function of time, under different conditions of conductivity and initial TP concentration in BOM at an applied electrical potential of $10 \mathrm{~V}$, are shown in Figs. 24.
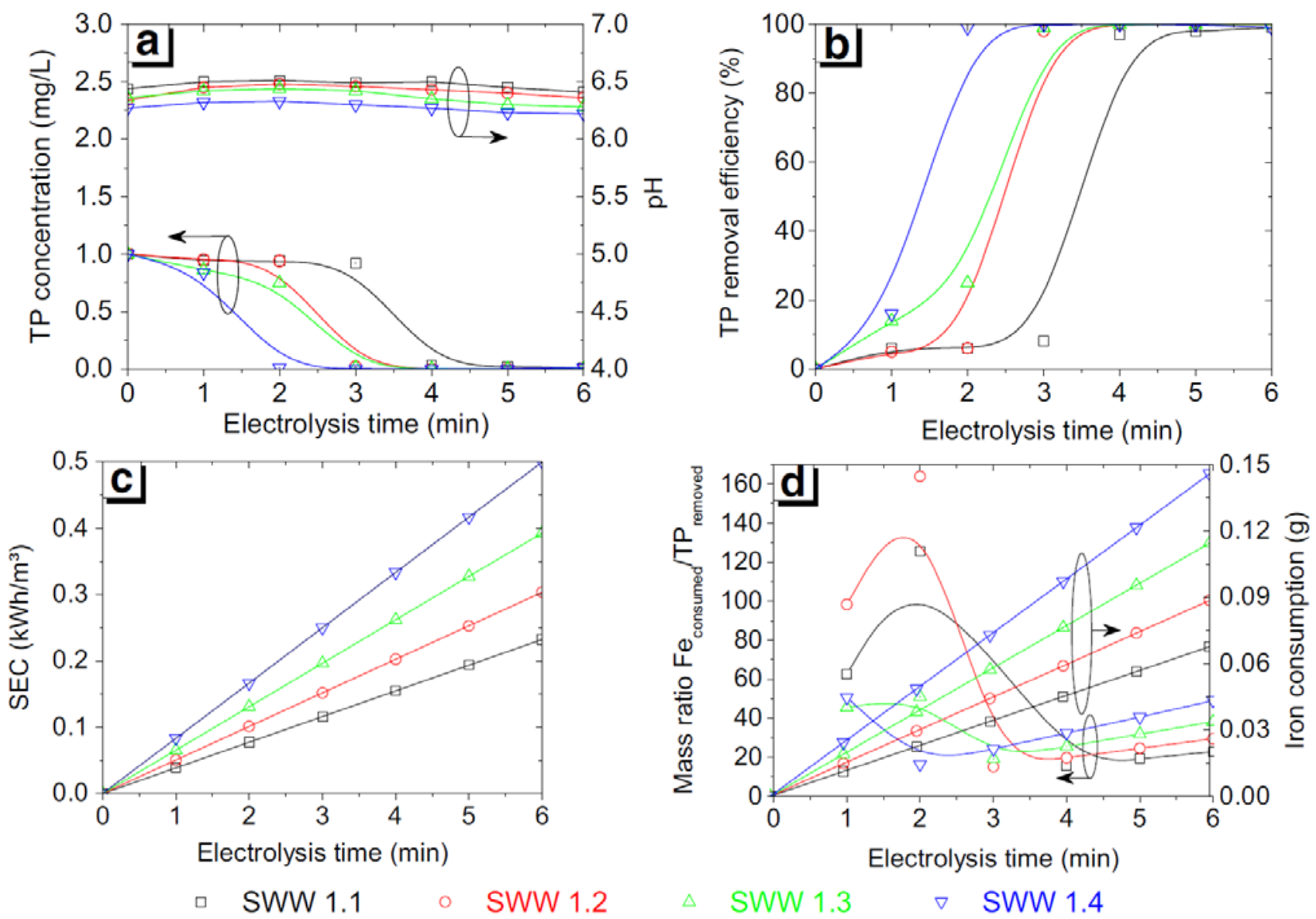

Fig. 2 Variations of $\mathrm{pH}$ and TP concentration (a), TP removal efficiency (b), SEC (c), and mass ratio of $\mathrm{Fe} / \mathrm{TP}$ and SIC (d) as a function of time at different conductivities in BOM at $10 \mathrm{~V}$ and an initial TP concentration of $1.0 \mathrm{mg} / \mathrm{L}$ 
Table 1 Operating conditions and key experimental parameters of the EC process using SWW

\begin{tabular}{|c|c|c|c|c|c|c|}
\hline \multirow{2}{*}{\multicolumn{2}{|c|}{$\begin{aligned} & \text { Experiment no. } \text { NaCl conc } \\
&(\text { wt.\%) } \text { Avg. } \\
&\end{aligned}$}} & \multirow{2}{*}{$\begin{array}{l}\text { Volt } \\
\text { (V) } \\
\text { Avg. }\end{array}$} & \multirow{2}{*}{$\begin{array}{l}\text { Conductivity } \\
(\mu \mathrm{S} / \mathrm{cm}) \\
\text { Avg. } \pm \text { Stdev }\end{array}$} & \multirow{2}{*}{$\begin{array}{l}\text { Current } \\
\text { (A) } \\
\text { Avg. } \pm \text { Stdev }\end{array}$} & \multicolumn{2}{|c|}{$\begin{array}{l}\text { Current density pH } \\
\left(\mathrm{A} / \mathbf{m}^{2}\right)\end{array}$} \\
\hline & & & & & Avg. \pm Stdev & Avg. \pm Stdev \\
\hline \multicolumn{7}{|c|}{ Operating in batch mode (BOM) } \\
\hline \multicolumn{7}{|l|}{ Series 1} \\
\hline SWW1.1 & 0.02 & 10 & $455.57 \pm 0.53$ & $0.65 \pm 0.00$ & $19 \pm 0.0$ & $6.47 \pm 0.04$ \\
\hline SWW1.1 & 0.02 & & $455.57 \pm 0.53$ & $0.65 \pm 0.00$ & $19 \pm 0.0$ & $6.47 \pm 0.04$ \\
\hline SWW1.2 & 0.03 & & $663.86 \pm 1.07$ & $0.85 \pm 0.00$ & $24.85 \pm 0.0$ & $6.42 \pm 0.05$ \\
\hline SWW1.3 & 0.04 & & $893.86 \pm 1.21$ & $1.1 \pm 2.4 \mathrm{E}-16$ & $32.16 \pm 0.0$ & $6.37 \pm 0.06$ \\
\hline SWW1.4 & 0.05 & & $1100.71 \pm 2.43$ & $1.4 \pm 2.4 \mathrm{E}-16$ & $40.93 \pm 0.0$ & $6.28 \pm 0.04$ \\
\hline \multicolumn{7}{|l|}{ Serial 2} \\
\hline SWW2.1 & 0.02 & 10 & $443.57 \pm 1.9$ & $0.6 \pm 0.00$ & $17.54 \pm 0.0$ & $6.60 \pm 0.06$ \\
\hline SWW2.2 & 0.03 & & $684.29 \pm 1.38$ & $0.85 \pm 0.00$ & $24.85 \pm 0.0$ & $6.51 \pm 0.04$ \\
\hline SWW2.3 & 0.04 & & $899.57 \pm 2.99$ & $1.15 \pm 2.4 \mathrm{E}-16$ & $33.62 \pm 0.0$ & $6.44 \pm 0.05$ \\
\hline SWW2.4 & 0.05 & & $1126 \pm 3.06$ & $1.4 \pm 2.4 \mathrm{E}-16$ & $40.93 \pm 0.0$ & $6.42 \pm 0.03$ \\
\hline \multicolumn{7}{|l|}{ Serial 3} \\
\hline SWW3.1 & 0.02 & 10 & $477.86 \pm 3.18$ & $0.65 \pm 0.00$ & $19 \pm 0.0$ & $6.40 \pm 0.03$ \\
\hline SWW3.2 & 0.03 & & $687.14 \pm 4.53$ & $0.9 \pm 0.00$ & $26.31 \pm 0.0$ & $6.42 \pm 0.02$ \\
\hline SWW3.3 & 0.04 & & $944 \pm 3.79$ & $1.2 \pm 0.00$ & $35.08 \pm 0.0$ & $6.41 \pm 0.02$ \\
\hline SWW3.4 & 0.05 & & $1149.29 \pm 3.9$ & $1.4 \pm 2.4 \mathrm{E}-16$ & $40.93 \pm 0.0$ & $6.40 \pm 0.02$ \\
\hline \multicolumn{7}{|c|}{ Operating in continuous mode (COM) } \\
\hline \multicolumn{7}{|l|}{ Series 4} \\
\hline SWW4.1 & Not added & 10 & $539.11 \pm 3.55$ & $3.33 \pm 0.1$ & $13.37 \pm 0.42$ & $8.08 \pm 0.52$ \\
\hline SWW4.2 & & & $528.89 \pm 1.05$ & $2.88 \pm 0.05$ & $11.56 \pm 0.21$ & $8.63 \pm 0.23$ \\
\hline SWW4.3 & & & $531 \pm 2.27$ & $2.99 \pm 0.07$ & $12.01 \pm 0.3$ & $8.21 \pm 0.46$ \\
\hline SWW4.4 & & & $533.5 \pm 3.34$ & $2.97 \pm 0.06$ & $11.95 \pm 0.23$ & $8.20 \pm 0.61$ \\
\hline SWW4.5 & & & $535.88 \pm 3.48$ & $3.04 \pm 0.05$ & $12.21 \pm 0.19$ & $8.06 \pm 0.40$ \\
\hline
\end{tabular}

$S W W$ synthetic wastewater, $A v g$. average, Stdev standard deviation, Volt. voltage

The results depicted in Fig. 2a, b demonstrated that additional $\mathrm{NaCl}$ or increased conductivity in the influent wastewater with a constant applied potential of $10 \mathrm{~V}$ ensured a steady increase in phosphorus removal efficiency. The initial values of TP concentration and conductivity of the solution were $1.0 \mathrm{mg} / \mathrm{L}$ and $456 \mu \mathrm{S} / \mathrm{cm}$, respectively. It took only about 4 min for the EC process to achieve a steady state of $97 \%$, which corresponded to a final effluent TP concentration of $0.03 \mathrm{mg} / \mathrm{L}$. Conversely, if the conductivity was increased to $1101 \mu \mathrm{S} / \mathrm{cm}$, the removal efficiency of the EC process rose to $99 \%$ within 2 min of starting electrolysis. This corresponds to a final effluent TP concentration of $0.01 \mathrm{mg} / \mathrm{L}$. Thus, for SWW with an initial TP concentration of $1.0 \mathrm{mg} / \mathrm{L}$, approximately 2 min of electrolysis can increase the EC process' removal efficiency by 16.5 times when the conductivity of the solution is increased from 456 to $1101 \mu \mathrm{S} / \mathrm{cm}$. Results also indicate 
that, under the same experimental conditions, $\mathrm{NaCl}$ added directly to the solution will lead to a significant increase in TP reduction and shorter electrolysis time when compared to no addition of $\mathrm{NaCl}$. This was probably due to the increase in the amount of dissolved iron in solution, resulting in increased removal of TP. Meanwhile, as depicted in Fig. 2c, d, the SEC and SIC exhibited linear upward trends during the experimental period. The mass ratio of $\mathrm{Fe}_{\text {cons. }} / \mathrm{TP}$ rem. $(\mathrm{mg} / \mathrm{mg})$ is equal to the proportion of the mass of iron consumption and mass of total phosphorus removed. This ratio was considered for investigating the mechanism of TP removal.


- SWW $2.1 \quad \circ \quad$ SWW 2.2

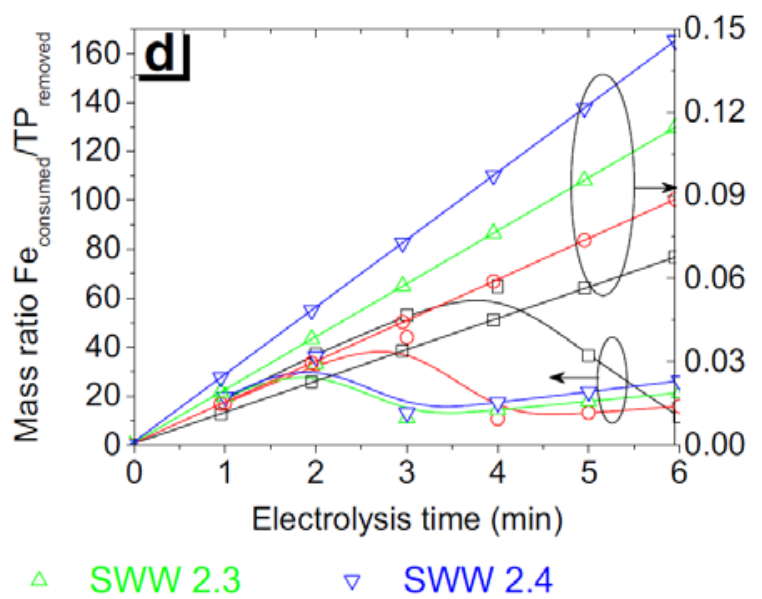

Fig. 3 Variations of $\mathrm{pH}$ and TP concentration (a), TP removal efficiency (b), SEC (c), and mass ratio of $\mathrm{Fe} / \mathrm{TP}$ and SIC (d) as a function of time at different conductivity in BOM at $10 \mathrm{~V}$ and initial TP concentration of $2.0 \mathrm{mg} / \mathrm{L}$

Similar to experiments with an initial TP concentration of $1.0 \mathrm{mg} / \mathrm{L}$, experiments using cylindrical iron electrodes were conducted with the initial TP concentration changed to 2.0 and $3.0 \mathrm{mg} / \mathrm{L}$. As can be seen from Figs. $3 \mathrm{a}$ and $4 \mathrm{a}$, the ability to remove TP exhibited a downward trend, which is similar to the experiments utilizing an initial TP concentration of $1.0 \mathrm{mg} / \mathrm{L}$ (Fig. 2a), with the residual TP concentration in the wastewater being directly proportional to conductivity. The ability to remove TP followed a first-order exponential decay relationship with electrolysis time. Partially, the results showed that phosphorus removal during the same elapsed electrolysis time was enhanced when adjusting solution conductivity by adding more $\mathrm{NaCl}$. For example, for experiments with an initial TP concentration of $2 \mathrm{mg} / \mathrm{L}$ and electrolysis time of $3 \mathrm{~min}$, the removals of TP (residual TP) were 10.5\% (1.97 mg/l), 18\% (1.6 mg/L), 98\% $(0.04 \mathrm{mg} / \mathrm{L})$, and 99\% $(0.02$ 
$\mathrm{mg} / \mathrm{L}$ ), which correspond to solution conductivities of 444, 684, 900, and $1126 \mu \mathrm{S} / \mathrm{cm}$, respectively (Fig. 3a, b). For experiments with an initial TP concentration of $3 \mathrm{mg} / \mathrm{L}$ and electrolysis time of 3 min, the removals of $9.67 \%(2.71 \mathrm{mg} / \mathrm{L}), 20.33 \%(2.39 \mathrm{mg} / \mathrm{L}), 82.33 \%(0.53 \mathrm{mg} / \mathrm{L})$, and $99.33 \%$ $(0.02 \mathrm{mg} / \mathrm{L}) \mathrm{TP}$ (residual TP) corresponded to solution conductivities of 4478, 684, 944, and 1149 $\mu \mathrm{S} / \mathrm{cm}$, respectively (Fig. 4a, b). These results are presented in Figs. 2a, 3a, and 4a as a function of operating time and show that the TP removal rate in BOM follows the first-order exponential decay equation.
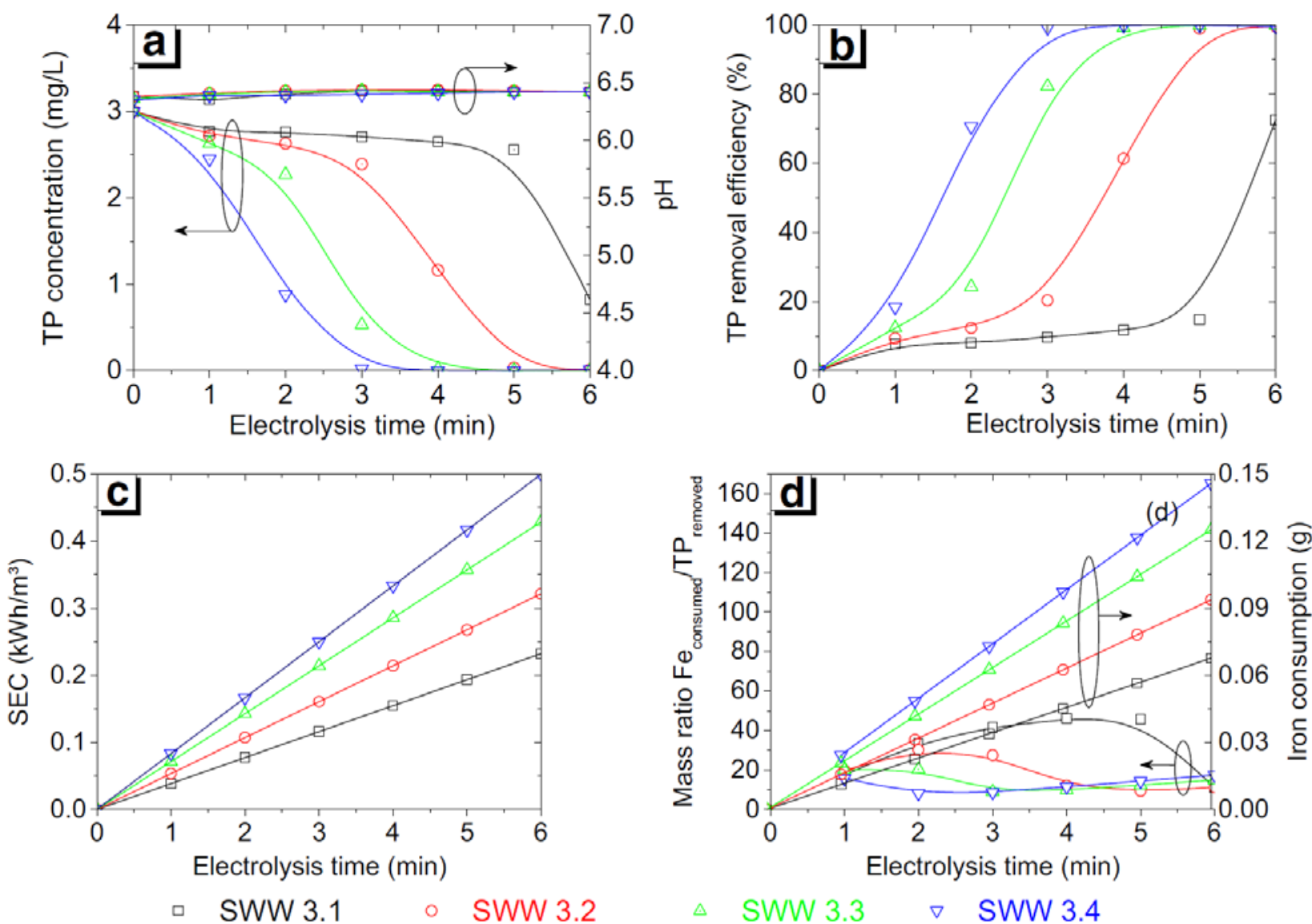

Fig. 4 Variation of $\mathrm{pH}$ and TP concentration (a), TP removal efficiency (b), SEC (c), and mass ratio of $\mathrm{Fe} / \mathrm{TP}$ and $\mathrm{SIC}(\mathbf{d})$ as a function of time at different conductivities in BOM at $10 \mathrm{~V}$ and initial TP concentration of $3.0 \mathrm{mg} / \mathrm{L}$

Under the same experimental conditions, a wastewater conductivity of $1125.3 \pm 20.55 \mu \mathrm{S} / \mathrm{cm}$ was required in order to achieve a residual TP concentration of less than $0.02 \mathrm{mg} / \mathrm{L}$ in the final effluent. The electrolysis time required for influent TP concentrations of 2, and $3 \mathrm{mg} / \mathrm{L}$ was 2, 2 to $3 \mathrm{~min}$, respectively. Meanwhile, if the conductivity of this solution is reduced to $678.4 \pm 10.95 \mu \mathrm{S} / \mathrm{cm}$, the minimum electrolysis time required increases to $3 \mathrm{~min}, 4$ to $6 \mathrm{~min}$, respectively.

The variations of SEC and SIC during 6 min of electrolysis in BOM, with different initial TP concentrations and varied $\mathrm{NaCl}$ concentration are shown in Figs. $\underline{2 c}, \mathrm{~d} ; \underline{3 \mathrm{c}, \mathrm{d}}$; and $\underline{4 \mathrm{c}, \mathrm{d}}$. These results indicate that SEC and SIC increase proportional to electrolysis time, with a constant applied voltage of $10 \mathrm{~V}$. SEC and SIC are very important parameters for the strategies used in choosing 
wastewater treatment technology. Based on this data, operating costs corresponding to the desired discharge requirements can be evaluated and effectively compared with other processes. The SEC and SIC in BOM fit very well to the first-order linear equations $\left(R^{2}>0.98\right)$ in our study (data not shown). They corresponded well to the concentration of TP (1-3 mg/L), applied voltage of $10 \mathrm{~V}$, and conductivity of solution ranges $(440-1150 \mu \mathrm{S} / \mathrm{cm})$.

The observed data also demonstrate that the influence of initial TP concentration on the SEC and SIC of the EC process is not apparent under the same conditions of conductivity and applied voltage of $10 \mathrm{~V}$.

Observations and resultant data are presented in Figs. 2d, 3d, and 4d. It emerged that the amount of iron electrode dissolved into wastewater could be calculated because it corresponded to the amount of TP, as measured concentrations were dealt with using the same experimental conditions. From this, it is possible to project the electrodes' real-time functional lifespan accurately. This will eliminate a major objection of operators opposed to using this technology. Instead, it will enable them to have a sophisticated (CPM/engineering based), predictable, real-time, and well-budgeted (reliable annual budgeting projections for system management and maintenance) plan in place for routine electrode replacement.

The results presented in Figs. 2a, b; 3a, b; and 4a, b demonstrate that the EC process in BOM with SWW successfully removed phosphorus from wastewater, with TP concentration in the final effluent reduced to $0.02 \mathrm{mg} / \mathrm{L}$ or below. The EC process is capable of very efficiently removing an exceptionally high initial amount of phosphorus of up to $3 \mathrm{mg} / \mathrm{L}$. Removal efficiency ranged from 72.67 to $100 \%$, corresponding to a conductivity that varied from 478 to $1149 \mu \mathrm{S} / \mathrm{cm}$ and $\mathrm{pH}$ values that varied in the neutral range of 6.22-6.66, even at a constant applied electrical potential of $10 \mathrm{~V}$. One hundred percent efficiency is an exceedingly high level for TP removal. Although this result has been achieved experimentally at the laboratory level, this technology seems to be reliable and is considered as a potential option for the removal of phosphorus in wastewater.

According to the evidence from the experiments mentioned above, the efficiency of phosphorus removal increased as either the electrolysis time, the solution conductivity, or both increased. The mass ratio of iron consumption per TP removed ( $\mathrm{Fe}_{\text {cons. }} / \mathrm{TP}_{\mathrm{rem}}$. $)(\mathrm{mg} / \mathrm{mg})$ was inversely proportional to conductivity in the carrier solution. This means that increasing the conductivity of the solution increases the efficiency of the EC process, shortens electrolysis time, and uses optimum levels of dissolved iron. However, it slightly raises SEC.

\subsection{Continuous EC system performance}

The configuration of the electrolysis devices used in the COM experiments followed a sophisticated design that employs twin, nested iron cylinders. This configuration provides ample surface area to ensure sufficient interparticle contact will occur, thus increasing the ionic mass transport coefficient needed to achieve the particulate agglomeration required for effective contaminant, specifically TP, removal. Furthermore, it provides a moderate vertical shearing stress created by the upward flow of wastewater caused by tiny bubbles of hydrogen and oxygen gases formed by the ionic electrolysis of $\mathrm{H}_{2} \mathrm{O}$. This secondary effect scours or "washes" the surface of the electrodes, minimizing the build-up of insoluble hydroxides and sludge layers on the electrode surface. This, 
in turn, ensures that the iron surface is adequately exposed to the solution and maintains stable performance of the EC process in-situ, for the life of the electrode. To create this harmonious combination of processes, slightly more electrical power consumption is required; however, this is easily offset by the optimum removal efficiency of the technology. The resultant corrosion on the surface of the electrodes will be homogeneous, and consequently, the lifetime of the anode can be guaranteed for a long period. Additionally, local fabrication is readily available worldwide at reasonable cost. To improve the performance of the EC process in both COM and BOM, the polarity of the electrode was also alternated frequently.

A series of experiments was conducted with SWW in COM. Samples were taken from the effluent of the EC reactor at predetermined flow rate values of $8.5,8,7,6,5,4,3$, and $2 \mathrm{~L} / \mathrm{min}$, which corresponded to the electrolysis times of $0.78,0.83,0.95,1.11,1.33,1.66,2.22$, and 3.33 min (Table 1).

The following experiments were carried out for this study: COM at an applied steady voltage of $10 \mathrm{~V}$, the effects of initial TP concentration and flow rate on efficiency in removing phosphorus based on SEC, and resulting anode SIC rates (Fig. ㄱ). To determine the optimum retention time, the SEC and SIC were evaluated based on these results.
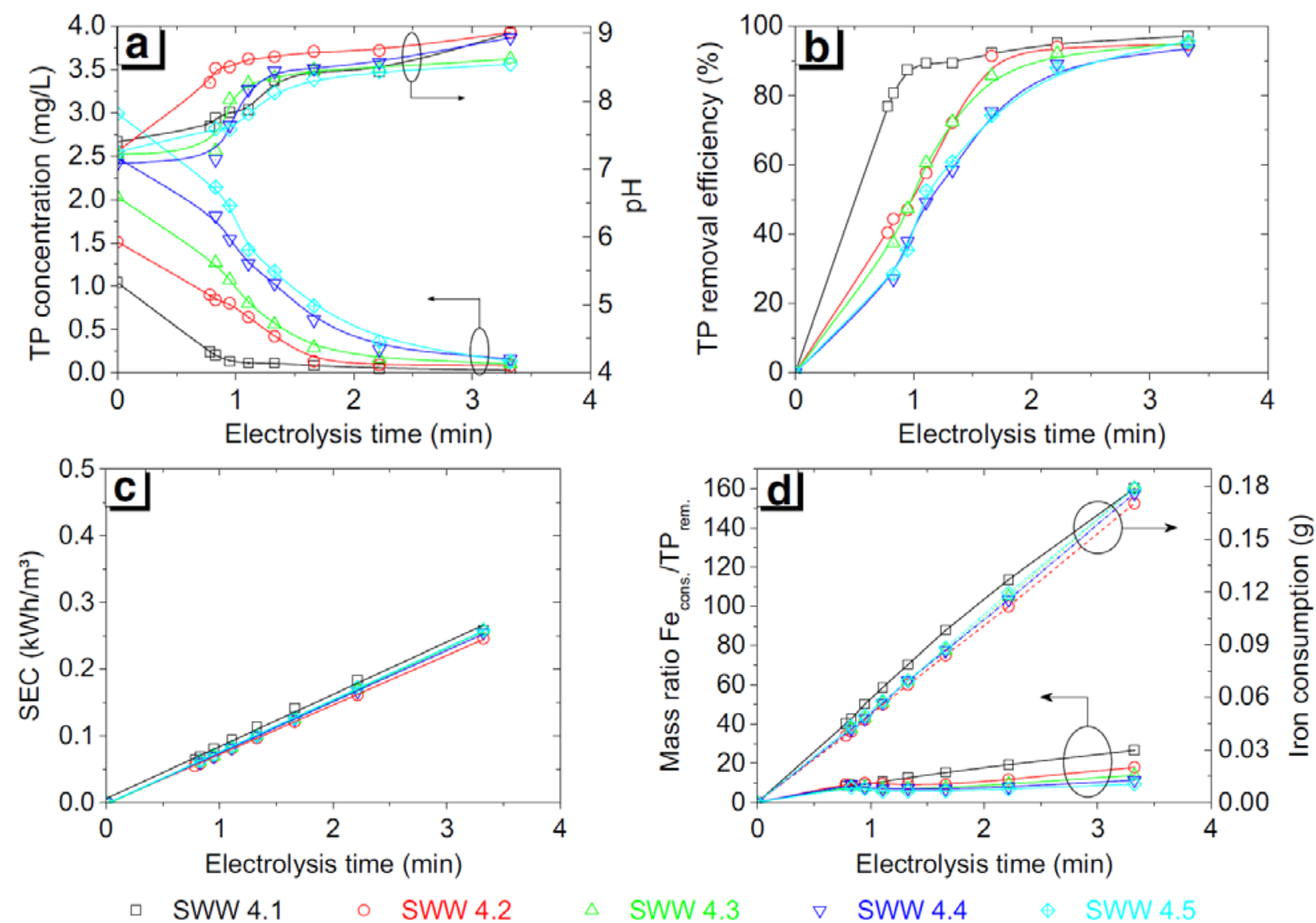

Fig. 5 Variation of $\mathrm{pH}$ and TP concentration (a), TP removal efficiency (b), SEC (c), and mass ratio of Fe/TP and SIC (d) as a function of time at different initial TP concentrations in COM at $10 \mathrm{~V}$ 
The EC process was implemented by changing the initial TP concentrations of 1.04, 1.51, 2.03, 2.48 , and $2.99 \mathrm{mg} / \mathrm{L}$, respectively. Meanwhile, experimental wastewater was retained in the actual wastewater scenario (e.g., temp., $\mathrm{pH}$, conductivity). These correspond to the residual TP concentrations measured at the flow rate of $2 \mathrm{~L} / \mathrm{min}$ (electrolysis time of $3.33 \mathrm{~min}$ ) and were $0.03 \mathrm{mg} / \mathrm{L}$ (97.12\%), $0.08 \mathrm{mg} / \mathrm{L}$ (94.7\%), $0.1 \mathrm{mg} / \mathrm{L}$ (95.07\%), $0.16 \mathrm{mg} / \mathrm{L}$ (93.55\%), and $0.13 \mathrm{mg} / \mathrm{L}$ (95.65\%), respectively. Observing the plotted results in Fig. 5 led to the conclusion that when the electrolysis time increases, TP removal efficiency in COM improves because it achieves greater iron release and longer contact time. Together the $\mathrm{pH}$ value also tends to rise (7.08-9.01, within the parameter ranges studied), owing to various iron hydroxides formed and hydrogen ion removal by cathodic reactions during EC. In contrast, the flow rate tends to decrease and the SEC and SIC tend to increase.

When the electrolysis time was less than $2.22 \mathrm{~min}$ (at a flow rate of more than $3 \mathrm{~L} / \mathrm{min}$ ), TP removal efficiency increased at a rate inversely proportional to the initial TP concentrations. For example, sample analysis after $0.95 \mathrm{~min}$ of treatment time (at a flow rate of $7 \mathrm{~L} / \mathrm{min}$ ) demonstrated that the TP removal efficiencies for experiments with initial TP concentrations of 1.04, 1.51, 2.03, 2.48, and $2.99 \mathrm{mg} / \mathrm{L}$ were $87.50 \%(0.13 \mathrm{mg} / \mathrm{l}), 47.02 \%(0.80 \mathrm{mg} / \mathrm{L}), 47.29 \%(1.07 \mathrm{mg} / \mathrm{L}), 37.9 \%$ $(1.54 \mathrm{mg} / \mathrm{L})$, and $35.45 \%(1.93 \mathrm{mg} / \mathrm{L})$, respectively. Meanwhile, if the electrolysis time was longer than $2.22 \mathrm{~min}$ (at a flow rate of less than $3 \mathrm{~L} / \mathrm{min}$ ) and the initial TP concentration rose from 1.04 to $2.99 \mathrm{mg} / \mathrm{L}$, TP treatment efficiency did not seem to change much. For example, sample analysis after $3.33 \mathrm{~min}$ of treatment (at a flow rate of $2 \mathrm{~L} / \mathrm{min}$ ) demonstrated TP removal efficiencies for experiments with initial TP concentrations of 1.04, 1.51, 2.03, 2.48, and $2.99 \mathrm{mg} / \mathrm{L}$ were $97.12 \%$ $(0.03 \mathrm{mg} / \mathrm{L}), \quad 94.7 \% \quad(0.08 \mathrm{mg} / \mathrm{L}), \quad 95.07 \% \quad(0.1 \mathrm{mg} / \mathrm{L}), \quad 93.55 \% \quad(0.16 \mathrm{mg} / \mathrm{L}), \quad$ and $95.65 \%$ $(0.13 \mathrm{mg} / \mathrm{L})$, respectively.

The results illustrate that the TP removal rates in COM experiments with differing initial TP concentrations seem almost equivalent. It is obvious that experiments with less influent TP, higher SEC, and more iron anode consumption are required, as the more iron that was dissolved, the greater the reduction in electrical energy consumption or level of TP removal.

The data show that higher flow rates enhance the reduction rate of phosphorus removal. This could be explained because an increase in flow rate causes a corresponding decrease in retention time, and so a larger volume of phosphorus was exposed to treatment during a short time period.

From the results for $\mathrm{Fe}_{\text {cons. }} / \mathrm{TP}_{\text {rem., }}$, shown in Figs. $2 \mathrm{~d}$, 3d, 4d, and 5d, it can be observed that in the initial period of the EC process, the mass ratio of $\mathrm{Fe}_{\text {cons. }} / \mathrm{TP}_{\text {rem. }}$ suddenly jumped to an unusually high level and became unstable within 2-5 min, depending on the original characteristics of the wastewater (such as initial TP concentration and initial conductivity). This can be explained by charge neutralization and coagulation. Following that, these ratios rapidly decreased to their optimum values, and afterward tended to increase slowly in stability when the curves of TP removal efficiency reached a plateau, indicating that the treatment was almost complete. In addition, it is noted that a large amount of iron was required for the actual operation compared to what was predicted based on the chemical reactions alone between iron ions and soluble orthophosphate to produce a precipitate. 
The experimental results indicate that the removal of TP in COM was more efficient compared to that in BOM under the same operating conditions. Based on these results, it also emerged that even under different operating conditions, removal efficiency increased when electrolysis time or voltage also increased. It is remarkable that this trend coincides with BOM.

\subsection{Statistical model verification and evaluation}

Based on experimental data, statistical model verification of RSM was applied to investigate and correctly describe the effects of independent/operational variables on the response functions, as well as to optimize the EC system's performance (Adjeroud et al. 2015) through controlled operating parameters and energy consumption.

The regression equation was fitted as a second-order response (as Eq. $\underline{5}$ ) for the application of the central composite design.

$$
y=\beta_{0}+\sum \beta_{\mathrm{j}} x_{\mathrm{j}}+\sum \beta_{\mathrm{jj}} x_{\mathrm{j}}^{2}+\sum \beta_{\mathrm{jk}} x_{\mathrm{j}} x_{\mathrm{k}}
$$

Where $y$ is the predicted response (dependent variables); $x_{\mathrm{j}}$ and $x_{\mathrm{k}}$ are independent variables; $\beta_{\mathrm{o}}$ is the intercept; and $\beta_{\mathrm{j}}, \beta_{\mathrm{jj}}$, and $\beta_{\mathrm{jk}}$ are the linear, quadratic, and interactive coefficients, respectively.

Experimental results obtained in both BOM and COM for the different conditions and in a previous study (Nguyen et al. 2014a) showed that, within the range studied, the $\mathrm{pH}$ and temperature did not significantly affect the EC system efficiency. Hence, $\mathrm{pH}$ was excluded from the regression equation.

The dependent (response) variables were the TP concentration in effluent $Y(\mathrm{mg} / \mathrm{L})$, TP removal efficiency for $Y(\%)$, and electrolysis energy consumption SEC $\left(\mathrm{kWh} / \mathrm{m}^{3}\right)$. The independent variables were the initial TP concentration $\left(x_{1}, \mathrm{mg} / \mathrm{L}\right)$, current density $\left(x_{2}, \mathrm{~A} / \mathrm{m} 2\right)$, electrolysis time $\left(x_{3}, t\right)$, conductivity $\left(x_{4}, \mu \mathrm{S} / \mathrm{cm}\right)$, and TP removal efficiency $\left(x_{5}, \%\right)$.

Iterative regression analyses of the experimental data and elimination of the terms did not result in a statistical significance $(p>0.05)$. The empirical polynomial equation explains the interactive effects between each independent variable on the response variables in BOM and COM processes, to obtain the following second-order polynomial equations (Eqs. 6-8).

$$
\begin{aligned}
Y_{\text {BOм }}(\mathrm{mg} / \mathrm{L})= & -2.258+1.210 x_{1}-0.007 x_{2}+1.614 x_{3} \\
& +0.003 x_{4}-0.147 x_{3}^{2}-0.001 x_{1} x_{4}-0.002 x_{3} x_{4} \\
& \left(n=43, p<0.001, R^{2}=0.894\right) \\
Y_{\mathrm{COM}}(\mathrm{mg} / \mathrm{L})= & -968.778-21.531 x_{1}-9.027 x_{2}+4.085 x_{3} \\
& +3.891 x_{4}-0.162 x_{2}^{2}+0.22 x_{3}^{2}-0.004 x_{4}^{2} \\
& -0.442 x_{1} x_{2}-0.241 x_{1} x_{3}+0.052 x_{1} x_{4} \\
& +0.24 x_{2} x_{3}+0.025 x_{2} x_{4}-0.015 x_{3} x_{4} \\
& \left(n=37, p<0.001, R^{2}=0.993\right)
\end{aligned}
$$




$$
\begin{aligned}
& Y_{\text {BOM }}(\%)=39.591+ 6.298 x_{1}+0.852 x_{2}-44.053 x_{3} \\
&-0.096 x_{4}+5.526 x_{3}^{2}-6.781 x_{1} x_{3}+0.077 x_{3} x_{4} \\
&\left(n=43, p<0.001, R^{2}=0.828\right) \\
& Y_{\text {Сом }}(\%)=43389.2+432.6 x_{1}+27.4 x_{2}-195.5 x_{3}-163.3 x_{4} \\
&-10 x_{3}^{2}+0.2 x_{4}^{2}+5.4 x_{1} x_{3}-0.8 x_{1} x_{4}-12.4 x_{2} x_{3} \\
&+0.7 x_{3} x_{4}\left(n=37, p<0.001, R^{2}=0.987\right) \\
& \operatorname{SEC}_{\text {Bом }}\left(\mathrm{kWh} / \mathrm{m}^{\hat{E}}\right)=-0.227+0.004 x_{1}+0.010 x_{2}+0.077 x_{3} \\
&-3.0 \times 10^{-6} x_{4}+2.54 \times 10^{-4} x_{5}-9.6 \times 10^{-5} x_{2}^{2} \\
&-0.005 x_{3}^{2} \\
&\left(n=43, p<0.001, R^{2}=0.977\right) \\
& \operatorname{SEC}_{\text {СOм }}\left(\mathrm{kWh} / \mathrm{m}^{E}\right)= 0.736-0.051 x_{1}-0.050 x_{2}-0.002 x_{3} \\
&-0.001 x_{4}+4 \times 10^{-4} x_{5}-0.002 x_{1} x_{2}-5 \\
& \times 10^{-4} x_{1} x_{3}+10^{-4} x_{1} x_{4}+5 \times 10^{-5} x_{1} x_{5} \\
&+0.006 x_{2} x_{3}+10^{-4} x_{2} x_{4}-4 \times 10^{-5} x_{2} x_{5} \\
&\left(n=37, p<0.001, R^{2}=0.999\right)
\end{aligned}
$$

Results of the analysis of variance from all responses indicate that the regression of the reduced second-order polynomial models was statistically significant and reliable, with values of the determination coefficient of $R^{2}>0.82$ and probability $(p)$ value $<0.001$ in both modes (BOM and $\mathrm{COM})$. This indicated that more than $82 \%$ of the total variations can be explained by the regression model. This means that there were significant interactions among the independent variables of initial TP concentration, current density, electrolysis time, and conductivity, and they could contribute significantly to EC performance efficiency, but their degree of contribution differed from BOM to COM (Eqs. 6-8).

Equation 6a, b and Figs. S1 and S2 indicate that in both operating modes, the initial TP concentration $\left(x_{1}\right)$ and electrolysis time $\left(x_{3}\right)$ had greater effects on TP reduction rate and TP removal efficiency as compared to current density $\left(x_{2}\right)$ and solution conductivity $\left(x_{4}\right)$. Meanwhile, the current density $\left(x_{2}\right)$ and electrolysis time $\left(x_{3}\right)$ had a greater effect on the energy consumption as compared to initial TP concentration $\left(x_{1}\right)$ and solution conductivity $\left(x_{4}\right)$. Similar to the results of the above experiments, the results of the regression correlation analysis also suggest that the TP reduction rates in the effluent and TP removal efficiencies of the EC process increased as either or whole current density $\left(x_{2}, \mathrm{~A} / \mathrm{m} 2\right)$, electrolysis time $\left(x_{3}, \min .\right)$, and conductivity $\left(x_{4}, \mu \mathrm{S} / \mathrm{cm}\right)$ increased. Parallel to this, the corresponding power requirements also increased. Consequently, it is recommended to balance TP removal efficiency and power requirement (cost-effectiveness).

The distribution plots of the actual and predicted values for all responses of TP concentration in the effluent, TP removal efficiency, and electrolysis energy consumption are demonstrated in 
Figs. $6(\mathrm{BOM})$ and $7(\mathrm{COM})$. As indicated, the coefficient of correlations were found to be higher than 0.92 and 0.98 in BOM and COM, respectively. It can, therefore, be concluded from Figs. 6 and 7 that good correlation exists between the proposed model and the experimental results for both operating modes, confirming that the fitted model was considered adequate to reflect the expected optimum operating ranges in order to obtain optimum TP reduction and energy consumption.
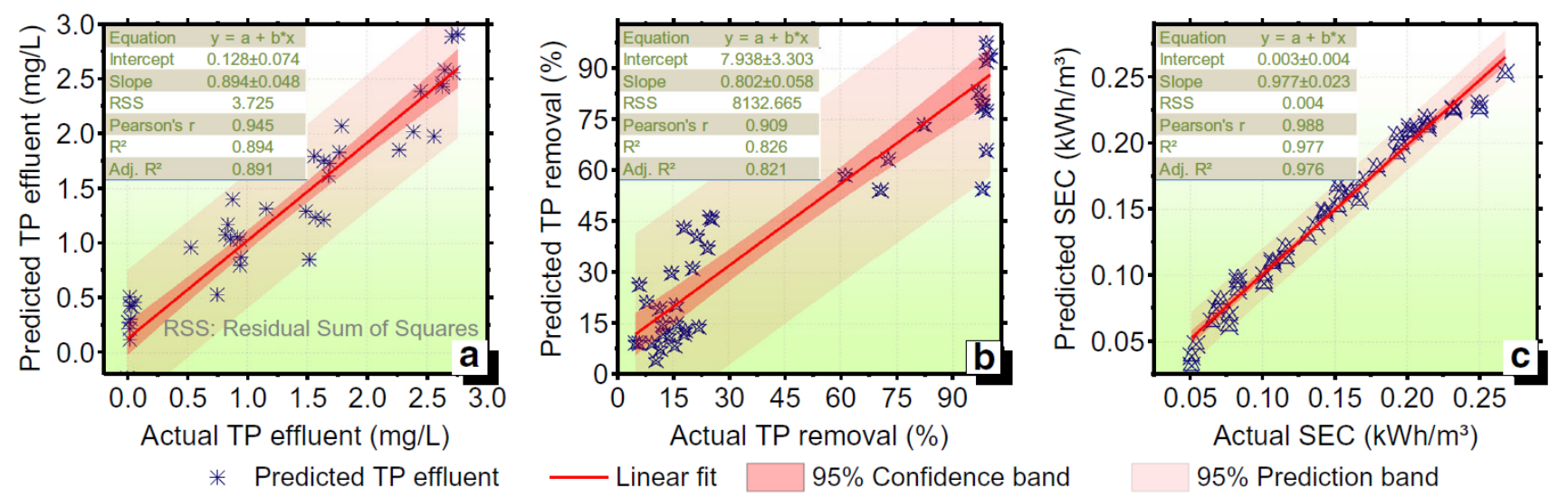

Fig. 6 Experimental data versus predicted values for TP concentration in effluent (a), TP removal efficiency (b), and SEC (c) in BOM


Fig. 7 Experimental data versus predicted values for TP concentration in effluent (a), TP removal efficiency (b), and SEC (c) in COM

\section{Conclusions}

Both configuration and operating mode of EC were exhaustively investigated and evaluated under various conditions for phosphorus removal performance. The remarkable results are summarized as follows:

- The EC process was excellent performance for treating phosphorus in wastewater. It can potentially use scrap iron for the electrodes, thus reducing the system's operational costs. However, a large amount of iron was required for the actual operation compared to what was estimated based on the chemical reactions alone between iron ions and soluble orthophosphate to produce a precipitate. 
- Rate and efficiency of phosphorus removal significantly depend on the wastewater conductivity, current density, initial phosphorus concentration, and electrolysis time.

- In the same period of electrolysis time, phosphorus removal rate in continuous EC operation is faster than in batch EC operation.

- The proposed model for the effect of independent variables on the response functions was highly significant with very low probability values $(<0.001)$ and reasonably matched the experimental data in this study. It also demonstrated that optimum operation performance of the EC process can be achieved by controlling and adjusting the operating parameters.

\section{Acknowledgements}

We are grateful for the research collaboration between Kyonggi University and the University of Technology Sydney. We would also like to thank Dankook University, Gentro Co., Ltd., and former President Dr. S. D. Kim for this research material and advice that made completion of this work possible.

\section{Appendix A. Supplementary material}

Supplementary data associated with this article can be found, in the online version, at https://doiorg.ezproxy.lib.uts.edu.au/10.1007/s11356-017-0180-2.

\section{References}

Adjeroud N, Dahmoune F, Merzouk B, Leclerc J-P, Madani K (2015) Improvement of electrocoagulation-electroflotation treatment of effluent by addition of Opuntia ficus indica pad juice. Sep Purif Technol 144:168-176.

Akbal F, Camci S (2011) Copper, chromium and nickel removal from metal plating wastewater by electrocoagulation. Desalination 269:214-222.

Al-Harahsheh M, Batiha M, Kraishan S, Al-Zoubi H (2014) Precipitation treatment of effluent acidic wastewater from phosphate-containing fertilizer industry: characterization of solid and liquid products. Sep Purif Technol 123:190-199.

Anderson DM, Glibert PM, Burkholder JM (2002) Harmful algal blooms and eutrophication: nutrient sources, composition, and consequences. Estuaries 25:704-726.

Anderson DM, Burkholder JM, Cochlan WP, Glibert PM, Gobler CJ, Heil CA, Kudela RM, Parsons ML, Rensel JEJ, Townsend DW, Trainer VL, Vargo GA (2008) Harmful algal blooms and eutrophication: examining linkages from selected coastal regions of the United States. Harmful Algae 8:39-53.

Bayar S, Yilmaz AE, Boncukcuoğlu R, Fìl BA, Kocakerìm MM (2013) Effects of operational parameters on cadmium removal from aqueous solutions by electrochemical coagulation. Desalin Water Treat 51:2635-2643.

Bayar S, Boncukcuoğlu R, Yilmaz AE, Fil BA (2014) Pre-treatment of pistachio processing industry wastewaters (PPIW) by electrocoagulation using Al plate electrode. Sep Sci Technol 49:10081018.

Can BZ, Boncukcuoglu R, Yilmaz AE, Fil BA (2014) Effect of some operational parameters on the arsenic removal by electrocoagulation using iron electrodes. J Environ Health Sci Eng 12:95.

Chen G (2004) Electrochemical technologies in wastewater treatment. Sep Purif Technol 38:11-41. 
Conley DJ, Paerl HW, Howarth RW, Boesch DF, Seitzinger SP, Havens KE, Lancelot C, Likens GE (2009) Controlling eutrophication: nitrogen and phosphorus. Science 323:1014-1015.

Daneshvar N, Oladegaragoze A, Djafarzadeh N (2006) Decolorization of basic dye solutions by electrocoagulation: an investigation of the effect of operational parameters. J Hazard Mater 129:116-122.

Deliyanni EA, Peleka EN, Lazaridis NK (2007) Comparative study of phosphates removal from aqueous solutions by nanocrystalline akaganéite and hybrid surfactant-akaganéite. Sep Purif Technol 52:478-486.

Heisler J, Glibert PM, Burkholder JM, Anderson DM, Cochlan W, Dennison WC, Dortch Q, Gobler CJ, Heil CA, Humphries E, Lewitus A, Magnien R, Marshall HG, Sellner K, Stockwell DA, Stoecker DK, Suddleson M (2008) Eutrophication and harmful algal blooms: a scientific consensus. Harmful Algae 8:3-13.

Hosni K, Ben Moussa S, Ben Amor M (2007) Conditions influencing the removal of phosphate from synthetic wastewater: influence of the ionic composition. Desalination 206:279-285.

Huang H, Liu J, Ding L (2015) Recovery of phosphate and ammonia nitrogen from the anaerobic digestion supernatant of activated sludge by chemical precipitation. J Clean Prod 102:437-446.

Huang H, Zhang D, Zhao Z, Zhang P, Gao F (2017) Comparison investigation on phosphate recovery from sludge anaerobic supernatant using the electrocoagulation process and chemical precipitation. J Clean Prod 141:429-438.

Lacasa E, Cañizares P, Sáez C, Fernández FJ, Rodrigo MA (2011) Electrochemical phosphates removal using iron and aluminium electrodes. Chem Eng J 172:137-143.

Lai TM, Dang HV, Nguyen DD, Yim S, Hur J (2011) Wastewater treatment using a modified A2O process based on fiber polypropylene media. J Environ Sci Health A 46:1068-1074.

Li Y, Liu C, Luan Z, Peng X, Zhu C, Chen Z, Zhang Z, Fan J, Jia Z (2006) Phosphate removal from aqueous solutions using raw and activated red mud and fly ash. J Hazard Mater 137:374-383.

Lin L, Wan C, Lee D-J, Lei Z, Liu X (2014) Ammonium assists orthophosphate removal from highstrength wastewaters by natural zeolite. Sep Purif Technol 133:351-356.

Martínez-Huitle CA, Brillas E (2009) Decontamination of wastewaters containing synthetic organic dyes by electrochemical methods: a general review. Appl Catal B Environ 87:105-145.

Mollah MYA, Morkovsky P, Gomes JAG, Kesmez M, Parga J, Cocke DL (2004) Fundamentals, present and future perspectives of electrocoagulation. J Hazard Mater 114:199-210.

Monclús H, Sipma J, Ferrero G, Comas J, Rodriguez-Roda I (2010) Optimization of biological nutrient removal in a pilot plant UCT-MBR treating municipal wastewater during start-up. Desalination 250:592-597.

Nguyen D-D, Kim S-D, Yoon Y-S (2014a) Enhanced phosphorus and COD removals for retrofit of existing sewage treatment by electrocoagulation process with cylindrical aluminum electrodes. Desalin Water Treat 52:2388-2399.

Nguyen DD, Ngo HH, Yoon YS (2014b) A new hybrid treatment system of bioreactors and electrocoagulation for superior removal of organic and nutrient pollutants from municipal wastewater. Bioresour Technol 153:116-125.

Nguyen DD, Ngo HH, Guo W, Nguyen TT, Chang SW, Jang A, Yoon YS (2016) Can electrocoagulation process be an appropriate technology for phosphorus removal from municipal wastewater? Sci Total Environ 563-564:549-556. 
Rajeshwar K, Ibanez JG (1997) Environmental electrochemistry: fundamentals and applications in pollution abatement. Elsevier Science \& Technology Books, Amsterdam pp 804.

Sommariva C, Converti A, Del Borghi M (1997) Increase in phosphate removal from wastewater by alternating aerobic and anaerobic conditions. Desalination 108:255-260.

Tran N, Drogui P, Blais J-F, Mercier G (2012) Phosphorus removal from spiked municipal wastewater using either electrochemical coagulation or chemical coagulation as tertiary treatment. Sep Purif Technol 95:16-25.

Wang X-H, Wang X, Huppes G, Heijungs R, Ren N-Q (2015) Environmental implications of increasingly stringent sewage discharge standards in municipal wastewater treatment plants: case study of a cool area of China. J Clean Prod 94:278-283,

Yang S, Yang F, Fu Z, Wang T, Lei R (2010) Simultaneous nitrogen and phosphorus removal by a novel sequencing batch moving bed membrane bioreactor for wastewater treatment. J Hazard Mater 175:551-557.

Ye Y, Ngo HH, Guo W, Liu Y, Zhang X, Guo J, B-j N, Chang SW, Nguyen DD (2016) Insight into biological phosphate recovery from sewage. Bioresour Technol 218:874-881.

Yildiz E (2004) Phosphate removal from water by fly ash using crossflow microfiltration. Sep Purif Technol 35:241-252.

Zelmanov G, Semiat R (2015) The influence of competitive inorganic ions on phosphate removal from water by adsorption on iron $(\mathrm{Fe}+3)$ oxide/hydroxide nanoparticles-based agglomerates. J Water Process Eng 5:143-152. 